Lembaran Volume 16 Number 1

Sejarah April 2020
ISSN 2314-1234 (Print)

ISSN 2620-5882 (Online)
Page

$62-70$

\title{
Islamisasi di Kota Surakarta dan Sekitarnya Masa Orde Baru: Sebuah Tinjauan Awal
}

\section{ADIF FAHRIZAL}

Program Studi Sejarah Peradaban Islam, IAIN Salatiga

Email: adiffahrizal@yahoo.com

\begin{abstract}
This article discusses the spread of Islam in the city and the neighborhood of Surakarta, Central Java during the New Order period. The spread of Islam took place through massive Islamic religious activities, such as mass prayer. In addition, the expansion of the number of mosques and mushola (Islamic praying sites) indicates a massive expansion of the influence of Islam in the region. Based on data from newspapers and interviews with relevant informants of the time, this article found out that the spread of Islam in Surakarta was a political agenda set up by the New Order government in order to counter the remnants of Communist ideology, which was withheld by sympathizers of the then Indonesian Communist Party. This article concludes that the massive spread of Islam shaped Surakarta, which had been known as the center of syncretic Javanese culture, to become religious and the government's fear of Communism could be reduced. However, the process also made a sharp dichotomy between Islamist-based and Javanese-based identity of the city.
\end{abstract}

\begin{abstract}
Abstrak
Artikel ini mengulas proses penyebaran ajaran Islam secara massif di Kota Surakarta dan sekitarnya pada masa Orde Baru. Proses penyebaran itu antara lain berlangsung melalui kegiatan pengajian dan penyelenggaraan acara-acara keagamaan Islam. Bertambahnya jumlah tempat ibadah di Kota Surakarta dan sekitarnya juga menunjukkan proses Islamisasi yang massif. Berdasarkan data dari sumber-sumber pemberitaan surat kabar dan wawancara, artikel ini menemukan bahwa Islamisasi atas Kota Surakarta dan sekitarnya pada masa Orde Baru merupakan proses by design, atau disengaja, oleh pemerintahan Orde Baru. Tujuannya adalah untuk melawan faham Komunis di wilayah tersebut, yang dipandang masih kuat pasca peristiwa 1965. Artikel menyimpulkan bahwa dengan massifnya penyebaran Islam di Surakarta pada masa Orde Baru, labelisasi Kota Solo sebagai pusat budaya Jawa yang sinkretis menjadi berkurang dan kekhawatiran akan penyebaran Komunisme dapat diatasi. Meskipun demikian, Surakarta pada masa Orde Baru menghadirkan dikotomi yang kuat antara kejawaan dan keislaman sebagai simbol identitas kota.. Ia juga melihat bagaimana civic design dan civic reform dengan menelusuri beragam governmentality yang berbeda, dari zaman kolonial sampai masa kini, guna memahami bagaimana pembentukkan arti place itu terbina secara historis tetapi juga secara politik dan strategis untuk kebutuhan orang-orang tinggal di dalamnya.
\end{abstract}

Keywords: AntiCommunist Movement; islamization; New Order; Surakarta

\section{Kata Kunci:} Gerakan AntiKomunis; islamisasi; Orde Baru; Surakarta 


\section{Pendahuluan}

Kurang lebih dalam dua dasawarsa terakhir bersamaan dengan maraknya aksi terorisme di Indonesia, Kota Surakarta (Solo) menjadi sorotan karena beberapa kasus yang berkaitan dengan terorisme terjadi di kota ini. Penyergapan para teroris kerap terjadi di Solo dan sekitarnya, bahkan gembong teroris asal Malaysia Noordin M. Top juga tewas dalam baku tembak dengan polisi di kota ini. Pada 2011 juga sempat terjadi peledakan bom di sebuah gereja di Solo yang menggunakan modus bom bunuh diri.

Apa yang membuat banyak orang terkejut adalah aksi-aksi teror itu terjadi di sebuah kota yang kerap dianggap adem-ayem, tentram, dan harmonis sebagaimana citra yang lazim melekat pada masyarakat Jawa Mataraman. Sesungguhnya jika kita menengok realitas sosio-historis Solo citra semacam itu jelas keliru. Setidaknya sejak awal abad ke-20 kota ini memang sudah sering diguncang gejolak sosial yang tidak jarang berbuntut pada tindak kekerasan. Kerusuhan anti-Cina, revolusi sosial anti-swapraja, sampai konflik antar pendukung partai politik mewarnai perjalanan sejarah Solo.

Tidak berlebihan kiranya jika dikatakan bahwa Solo sudah lama menjadi sarang radikalisme. Radikalisme ini mewujud dalam berbagai bentuk gerakan dengan ideologi yang berbeda. Pada awal abad ke-20 radikalisme rakyat Solo mewujud dalam bentuk gerakan anti-Cina yang dimotori Sarekat Islam (SI) dan kemudian gerakan anti-kolonialisme, kapitalisme, dan feodalisme di bawah PKI. Pada pertengahan abad ke-20 radikalisme di Solo mengambil bentuk gerakan anti-swapraja yang berhasil menghapuskan kekuasaan keraton baik Kasunanan maupun Mangkunegaran. Selanjutnya di era kemerdekaan ini PKI berhasil membangun basis yang solid di Solo sehingga Solo dikenal sebagai “daerah merah". Setelah hancurnya PKI dan berakhirnya rezim Demokrasi Terpimpin muncul lagi satu bentuk radikalisme lainnya, kali ini di bawah bendera Islam. Pada akhir 1970-an muncul kasus "Komando Jihad" yang menyeret sejumlah tokoh Islam di kota ini ke meja pengadilan dengan tuduhan subversif, berlanjut dengan timbulnya gerakan usroh pada dekade 1980-an yang menjadi cikal-bakal dari Jama'ah Islamiyah (JI) -organisasi bawah tanah yang para eksponennya banyak terlibat dalam aksi terorisme pada dasawarsa 2000-an.

Melihat perlintasan sejarah tersebut tampak bahwa radikalisme bukanlah hal baru di Solo. Akan tetapi menarik bahwa radikalisme yang menggunakan label Islam baru mulai marak di Solo pada masa Orde Baru sebelum kemudian meledak di era Reformasi. Hal ini tidak terlepas dari konteks sosial pada masa Orde Baru ketika dakwah Islam mendapat peluang untuk berkembang di kalangan kaum abangan yang sebelumnya diidentikkan dengan PKI -dan karenanya dalam batas-batas tertentu dakwah Islam inipun didukung oleh pemerintah Orde Baru sebagai bagian dari upaya mengikis 
pengaruh komunisme yang diidentikkan dengan ideologi anti-agama. Berkembangnya dakwah Islam di Solo membuka jalan bagi tumbuhnya pelbagai kelompok Islam dengan karakteristik yang berbeda satu dengan lainnya. Dalam kaitannya dengan hal tersebut perlu diingat bahwa kelompok radikal yang mengatasnamakan Islam bukanlah satu-satunya kelompok Islam yang muncul di Solo. Masih ada kelompok Islam lainnya yang tumbuh dan berkembang di Solo seiring dengan maraknya dakwah Islam pada masa Orde Baru. Penting untuk melihat secara historis bagaimana proses Islamisasi tersebut berlangsung di Solo, siapa saja pihak-pihak yang berperan di dalamnya dan bagaimana dampak proses ini terhadap wajah masyarakat Solo.

\section{Geliat Keislaman di Kota Bengawan}

Berkembangnya Islamisasi di Solo pada masa Orde Baru tidak bisa dilepaskan dari konteks sosial-politik pada awal Orde Baru maupun periode sebelumnya. Pada dekade 1950-an-1960-an Solo diwarnai ketegangan antar kekuatan politik yang secara garis besar dapat dibagi ke dalam dua kubu yaitu kubu komunis yang direpresentasikan oleh PKI dan kubu anti-komunis yang diwakili oleh Masyumi dan PNI. Setelah bubarnya Masyumi pada 1960 para aktivis Masyumi di Solo membentuk sejumlah wadah untuk menyalurkan aktivitasnya. Mereka yang semula aktif dalam politik mengalihkan aktivitasnya ke ranah dakwah meskipun sesungguhnya antara keduanya (dakwah dan politik) tidak bisa dipisahkan secara tegas terlebih pada era Demokrasi Terpimpin ketika politik menjadi panglima. Aktivitas dakwah yang dilakukan para eks-aktivis Masyumi di Solo sejatinya memiliki makna dan misi politis juga yaitu untuk melawan pengaruh PKI yang sedang berada di puncak kekuatannya.

Dalam rangka menghadapi propaganda yang massif dari PKI, pada 1964 sejumlah mantan aktivis Masyumi di Solo mendirikan Perguruan Tinggi Dakwah Islam (PTDI) yang berpusat di bekas kantor Partai Masyumi Surakarta di Kartopuran yang kemudian menjadi Gedung Umat Islam Surakarta. PTDI sengaja didirikan untuk menandingi gerakan PKI yang membentuk Universitas Rakjat (UR) yaitu lembaga yang memberikan pendidikan terbuka untuk masyarakat umum -semacam Universitas Terbuka sekarang ${ }^{1}$. Kegiatan PTDI sendiri meliputi pengajian dan kursus-kursus yang bersifat praktis. Sebelumnya, pada 1962 para mantan aktivis Masyumi di Solo juga membentuk Persatuan Dakwah dan Chutbah atau Pelaksana Tabligh dan Chutbah (Petapechut). ${ }^{2}$ Organisasi ini menempatkan para mubaligh dan khatib ke masjid-masjid yang ada di Solo.

1) Wawancara dengan Bapak Solihan Mahdum Cahyana (mantan aktivis Masyumi) tanggal 19 Mei 2014.

2) Ibid dan wawancara dengan Bapak Muhammad Amir (sesepuh Muhammadiyah Solo) tanggal 21 Mei 2014. 
Momentum bagi perkembangan dakwah Islam di Solo tiba pascagagalnya kudeta G-30-S/1965. Identifikasi dengan agama mendadak menjadi hal yang sangat penting, bahkan menyangkut hidup dan mati. Dampaknya adalah banyak orang yang semula tergolong Muslim nominal atau abangan berusaha menunjukkan dirinya sebagai Muslim yang taat agar tidak dicap sebagai PKI. Jumlah jamaah shalat Jum'at dan pengajian meningkat. ${ }^{3}$ Momentum ini dimanfaatkan oleh para aktivis Islam di Solo salah satunya lewat pengajian kuliah zhuhur di serambi Masjid Agung Kasunanan Surakarta yang diisi para mubaligh yang ada di Solo. Pengajian yang dimulai sejak 1964 dan masih berlangsung hingga sekarang ini menarik banyak pengunjung bahkan hingga mencapai ratusan orang. ${ }^{4}$ Pengajian kuliah zhuhur di serambi Masjid Agung ini mendapat dukungan penuh dari para pedagang batik Pasar Klewer. Dukungan diberikan baik lewat bantuan dana untuk keberlangsungan kegiatan pengajian maupun lewat suplai perlengkapan ibadah seperti sarung dan mukena bagi para peserta pengajian. ${ }^{5}$

Pemerintah Orde Baru yang baru berdiri dan hendak mengokohkan kekuasannya juga berusaha memanfaatkan kegiatan dakwah Islam. Pada 1967 Departemen Agama mengadakan program Pilot Project Pembinaan Mental Agama (P3A). Program ini pada dasarnya dibuat untuk mengadakan pembinaan agama di daerah-daerah yang sebelumnya menjadi basis PKI. Diasumsikan bahwa kuatnya PKI di daerah-daerah tersebut adalah karena lemahnya pengaruh agama di sana sehingga untuk mengikis sisa-sisa pengaruh PKI dipandang penting untuk mengadakan pembinaan agama di daerahdaerah semacam itu (Winardi, dalam: Sri Margana dan Widya Fitrianingsih (peny.), 2010: 408-428).. Di Solo program P3A mendapat sambutan hangat dari para aktivis Islam eks-Masyumi, mereka memanfaatkan P3A untuk berdakwah ke masyarakat. Para aktivis yang tergabung dalam PTDI maupun Petapechut masuk mengisi kegiatan-kegiatan pembinaan agama dalam P3A yang diselenggarakan di kampung-kampung. ${ }^{6}$ Dengan kata lain dalam hal ini terjadi simbiosis mutualisme antara para aktivis Islam dengan pemerintah Orde Baru sekalipun nantinya dalam politik antara keduanya sering tidak sejalan (Majalah Adil, 43/9 1975: 15). ${ }^{7}$

Aktivitas dakwah Islam di Solo berlangsung lewat banyak sarana. Sarana yang paling lazim adalah kegiatan pengajian yang masuk sampai ke kampung-kampung. Pengajian marak bermunculan di Solo pada masa

3) Ibid

4) Wawancara dengan Bapak Solihan Mahdum Cahyana.

5) Ibid

6) Wawancara dengan Bapak Solihan Mahdum Cahyana.

7) Yang menarik pejabat pemerintahan pun ikut serta dalam aktivitas dakwah di Solo, seperti yang dilakukan Residen Surakarta Subroto Yudosubroto yang mengisi pengajian pada 16 Februari 1975 di Keprabon 
Orde Baru, baik yang sifatnya rutin maupun insidental, yang cakupannya lokal kampung ataupun se-kota Surakarta. Banyak warga Solo yang antusias mengikuti pengajian yang tersebar di berbagai penjuru kota meskipun harus menempuh jarak yang cukup jauh. Di antara pengajian yang banyak didatangi warga Solo dan sekitarnya adalah pengajian para habaib (ulama keturunan Nabi Muhammad SAW) di Kampung Arab Pasar Kliwon. ${ }^{8}$ Selain itu ada pula pengajian rutin yang dilakukan oleh kelompok Pengajian Gabungan Surakarta. Kelompok yang dibentuk oleh kaum perempuan sejak tahun 1974 ini rutin mengadakan pengajian pada setiap minggu I dan III setiap bulan (Suara Bengawan, 5 Desember 1986). Kegiatan dan kelompok pengajian tidak hanya tumbuh di perkampungan lama tetapi juga di kawasan pemukiman baru seperti Perumnas Palur (Majalah Adil, 54/15 1986: 11-12).

Tradisi yang sudah lama hidup di Solo juga menjadi sarana dakwah Islam. Acara tahunan Sekaten yang dilangsungkan di alun-alun Kasunanan misalnya, diisi dengan pengajian dari para mubaligh yang ada di Solo (Majalah Adil, 43/11 1975: 14-15). Sebenarnya ini bukanlah hal baru mengingat dalam sejarahnya Sekaten adalah acara yang dibuat untuk merayakan kelahiran Nabi Muhammad SAW dan memang erat kaitannya dengan syi'ar Islam. Akan tetapi dalam perkembangannya kemudian Sekaten lebih banyak diwarnai acara hiburan sehingga menutupi bahkan menghilangkan fungsinya sebagai sarana dakwah. Tidak heran jika kemudian MUI Kotamadya Surakarta mengharap agar acara Sekaten dan Maleman Sriwedari tidak dilepaskan dari fungsi utamanya sebagai media dakwah Islam (Suara Bengawan, 21 Agustus 1986). Kesenian wayang tidak ketinggalan pula dijadikan sarana dakwah. Pada 1975 di Museum Radya Pustaka diselenggarakan pagelaran wayang kulit kreasi baru yang diberi nama "wayang kulit taqwa" dengan mengangkat lakon cerita masuknya Islam ke Tanah Jawa. Pagelaran wayang ini sendiri diselenggarakan oleh Rawatan Rohani Islam Korem 074 Surakarta (Majalah Adil, 43/9 1975: 13). Upaya memanfaatkan kesenian wayang sebagai sarana dayang juga dilakukan oleh Suryadi, seorang guru agama di SPG Muhammadiyah Klaten yang merangkap profesi sebagai dalang. Ia menciptakan wayang kreasi baru yang diberi nama "wayang sadat" (dari kata syahadat) dengan lakon cerita diambil dari kisah masuknya Islam di Tanah Jawa. Pertunjukan wayang kreasi Suryadi ini dipentaskan juga di Solo (Majalah Adil, 54/20 1986: 26-27).

Seiring dengan maraknya kegiatan dakwah, secara umum pada masa Orde Baru terlihat jelas adanya geliat keislaman masyarakat di Solo. Geliat ini ditandai dengan maraknya pembangunan masjid dan mushola di berbagai penjuru Kota Solo. Data statistik menunjukkan cenderung naiknya jumlah masjid di Solo dari tahun ke tahun sepanjang era Orde Baru.

8) Wawancara dengan Ibu Hadi Wisarno (Takmir Masjid Al Wustho Mangkunegaran) 5 Juni 2014. 
Tabel 1. Data Jumlah Masjid dan Langgar/Mushola di Solo Tahun 1969-1995*

\begin{tabular}{ccc}
\hline Tahun & Jumlah masjid & Jumlah langgar/mushola \\
\hline 1969 & 71 & 207 \\
1970 & 69 & 223 \\
1974 & 95 & 213 \\
1975 & 97 & 218 \\
1980 & 149 & 197 \\
1981 & 171 & 201 \\
1982 & 152 & 206 \\
1983 & 152 & 206 \\
1984 & 176 & 208 \\
1985 & 188 & 221 \\
1986 & 205 & 227 \\
1987 & 216 & 230 \\
1988 & 217 & 230 \\
1989 & 234 & 236 \\
1990 & 241 & 224 \\
1991 & 252 & 222 \\
1992 & 253 & 221 \\
1993 & 259 & 215 \\
1994 & 263 & 217 \\
1995 & 336 & 240 \\
\hline & &
\end{tabular}

Sumber: Buku statistik tahunan BPS Kota Surakarta.

*) Data jumlah rumah ibadah tahun 1971-1973, dan 1976-1979 tidak tersedia.

Berdirinya masjid di pelbagai penjuru Kota Solo terkadang berasal dari inisiatif pemerintah melalui program P2A (Proyek Pembinaan Agama -kelanjutan dari P3A) seperti dalam pembangunan sebuah masjid di Kadipiro tahun 1975 (Adil, 43/13 1975: 5). Namun kerap kali berdirinya masjid adalah inisiatif warga masyarakat sendiri. Pada 4 April 1986 misalnya, Walikota Solo R. Hartomo meresmikan sebuah masjid di Trangkilan, Kelurahan Sumber Kecamatan Banjarsari. Masjid yang diberi nama Masyithoh ini didirikan di atas tanah wakaf milik Sarwoko seorang hakim asal Solo yang tinggal di Medan Sumatra Utara. Pembangunan masjid ini sendiri yang menelan biaya Rp 10 juta dilakukan atas swadaya masyarakat. Dalam kesempatan peresmian itu walikota menyatakan bahwa proyek-proyek yang menyangkut peribadatan umat Islam mendapat perhatian dari Pemda (Suara Bengawan, 5 April 1986, 7 Juli 1986, 21 Agustus 1986). Pembangunan masjid tidak hanya berlangsung di kampung-kampung tetapi juga sampai di lingkungan Balai Kota. Pada bulan Oktober 1985 sebuah masjid yang diberi nama Baitul Hikmah diresmikan Wali Kota Hartomo di halaman depan Balai Kota Surakarta (Adil, 54/2 1985: 12-13). Akan tetapi dalam konteks politik keberadaan masjid dan langgar di Solo sewaktu-waktu juga bisa dipandang berbahaya oleh penguasa karena 
dijadikan tempat berlangsungnya kegiatan subversif. Masjid dan langgar disebut-sebut sebagai tempat pembinaan kader gerakan usroh Abdullah Sungkar yang anti-asas tunggal Pancasila dan hendak mendirikan Negara Islam (Suara Bengawan, 21 Agustus 1986; Solahuddin, 2011).

Gerakan usroh Abdullah Sungkar sendiri berawal dari institusi Islam lain yang juga tumbuh di Solo pada masa Orde Baru yaitu pondok pesantren. Abdullah Sungkar mendirikan Pondok Pesantren Al Mukmin di Dusun Ngruki Desa Cemani Kecamatan Grogol Sukoharjo -daerah pinggiran Solopada 1974. Sebelum mendirikan pesantren, Abdullah Sungkar sudah dikenal sebagai mubaligh yang aktif di Solo. Mantan aktivis Masyumi ini mengisi pengajian kuliah zhuhur di serambi Masjid Agung dan atas permintaan para pedagang batik di Pasar Klewer pengajiannya itu ditingkatkan menjadi pembelajaran di pesantren. Ia lalu mendirikan sebuah pesantren di daerah Gading Kidul pada 1972 yang dipindahkan ke Ngruki dua tahun kemudian di atas tanah wakaf salah seorang pedagang batik. ${ }^{9}$ Abdullah Sungkar dikenal sangat vokal menentang rezim Orde Baru sehingga harus beberapa kali keluar-masuk tahanan. Oleh karena aktivitas pendirinya yang anti-penguasa Pesantren Al Mukmin dicurigai sebagai pusat kegiatan subversif.

Al Mukmin bukanlah satu-satunya pesantren yang berdiri di Solo dan sekitarnya pada era Orde Baru. Sejumlah pesantren lain juga berdiri di Solo pada masa ini. Pada bulan November 1974 misalnya, dimulai pembangunan sebuah pondok pesantren di Kelurahan Sondakan Laweyan di atas tanah wakah dari almarhum H.A. Tafandi seluas kurang lebih $1200 \mathrm{~m} 2$ termasuk sebuah masjid (Adil, 43/4 1974: 34). Pada periode yang sama (tahun 1970-an) berdiri pula Pondok Pesantren Al Ahad di Perumnas Mojosongo Jebres. ${ }^{10} \mathrm{Di}$ antara pondok pesantren lain yang berdiri di Solo dan sekitarnya pada masa Orde Baru ini adalah Pondok Pesantren Assalaam yang berdiri tahun 1982 di Pabelan dan Pondok Pesantren Takmirul Islam di Tegalsari yang berdiri tahun 1985. Kedua pesantren ini mampu berkembang menjadi pesantren besar yang santrinya datang dari berbagai daerah.

Satu lagi penanda meningkatnya gairah keislaman di Solo dan sekitarnya adalah naiknya jumlah jemaah haji dari Solo. Jumlah jemaah haji terus meningkat dari tahun ke tahun sehingga hal ini merepotkan pihak Depag yang kekurangan tenaga yang membidangi pengurusan haji, seperti di Solo yang hanya memiliki 2 orang petugas yang mengurus haji. Anggota Persaudaraan Haji Surakarta hingga tahun 1986 mencapai lebih dari 5000 orang. Pada 1986 jumlah rombongan jemaah haji dari Solo berjumlah 193 orang. Di antara rombongan tersebut termasuk 2 orang mantan walikota dan penyanyi keroncong Waljinah (Suara Bengawan, 21 Juni 1986). Pergi hajinya Waljinah adalah suatu hal yang menarik karena ia sebelumnya tidak

9) Wawancara dengan Bapak Solihan Mahdum Cahyana.

10) Wawancara dengan Bapak Muhammad Amir. 
dikenal sebagai seorang yang religius terlebih ia adalah seorang penyanyi keroncong, sebuah dunia yang tampaknya jauh dari kesan 'Islami'. Peristiwa ini bisa dimaknai sebuah kepingan sangat kecil dari proses sosio-kultural yang sedang terjadi di Solo ketika itu yaitu adanya dorongan untuk menjalankan ajaran Islam yang dapat membuat seseorang teridentifikasi sebagai "Muslim yang taat".

\section{Penutup}

Pergantian rezim dari "Orde Lama" ke Orde Baru membawa dampak yang sangat besar dalam kehidupan masyarakat Indonesia, tidak hanya dalam aspek politik tetapi bahkan juga kehidupan beragama. Apa yang terjadi di Solo pada periode ini menunjukkan hal tersebut. Hancurnya PKI dan runtuhnya rezim Demokrasi Terpimpin membuka jalan bagi proses Islamisasi yang sebelumnya mendapat tantangan berat dari PKI -partai yang sering dipandang sebagai representasi dan pelindung identitas kaum abangan yang menolak ortodoksi Islam. Keberislaman menjadi penting karena erat kaitannya dengan keselamatan nyawa. Kondisi ini menimbulkan iklim yang kondusif bagi proses dakwah di tengah masyarakat Solo yang tergolong abangan.

Dalam proses ini terjadi simbiosis mutualisme antara para aktivis Islam dengan pemerintah Orde Baru. Baik para aktivis Islam maupun aparat negara sama-sama mempunyai peranan dalam proses dakwah di Solo pada masa Orde Baru. Sebagaimana halnya pemerintah kolonial, rezim Orde Baru membedakan antara Islam sebagai agama dengan Islam sebagai kekuatan politik. Islam sebagai agama harus dibiarkan bahkan didukung karena dipandang dapat memperkuat kekuasaan negara namun Islam sebagai kekuatan politik harus diwaspadai bahkan ditumpas.

Dalam kenyataan di lapangan sendiri pembedaan atas 2 jenis Islam ini tidak selalu punya pijakan yang riil. Tumbuh dan berkembangnya kesadaran keberagamaan masyarakat Solo secara tidak langsung menjadi lahan subur bagi kekuatan politik Islam. Munculnya gerakan usroh yang di kemudian hari bertransformasi menjadi JI menunjukkan hal ini. Terlepas dari itu kekuatan politik Islam seperti gerakan usroh bukan representasi satu-satunya dari kelompok Islam yang tumbuh di Solo pada zaman Orde Baru. Ada banyak kelompok Islam yang tumbuh dan berkembang di Solo dengan aneka ragam corak pemahaman dan praktik keberagamaannya.

Satu hal yang pasti, proses Islamisasi di Solo telah mengubah atau setidaknya memberi warna tersendiri wajah masyarakat maupun kota Solo. Maraknya pendirian masjid, mushola, dan pondok pesantren pada era Orde Baru -yang berlanjut hingga sekarang- membuat persepsi tentang Solo sebagai pusat budaya Jawa yang kerap dianggap sinkretis dan tidak Islami perlu dikaji ulang. Polarisasi identitas kejawaan dan keislaman yang pada masa pra-Orde Baru seolah terpisah dan bahkan saling berhadapan tampaknya tidak bisa lagi 
digunakan untuk memahami realitas sosio-kultural masyarakat Solo pada masa Orde Baru dan sesudahnya. Seberapa jauh Islam mentransformasikan kultur masyarakat dan sebaliknya sejauh mana masyarakat dengan kulturnya yang sudah melekat sejak lama menegosiasikan Islam dengan kultur tersebut menarik untuk dikaji lebih lanjut.

\section{Referensi}

\section{Koran dan Majalah}

Adil tahun ke-43 (1974) No. 4

Adil tahun ke-43 (1975) No. 9

Adil tahun ke-43 (1975) No. 11

Adil tahun ke-43 (April 1975) No. 13

Adil tahun ke-54 (Oktober 1985) No. 2

Adil tahun ke-54 (Mei 1986) No. 15

Adil tahun ke-54 (Juni 1986) No. 20

Suara Bengawan, 5 April 1986

Suara Bengawan, 21 Juni 1986

Suara Bengawan, 21 Agustus 1986

Suara Bengawan, 5 Desember 1986

\section{Sumber Lisan}

Wawancara dengan Bapak Solihan Mahdum Cahyana (mantan aktivis Masyumi) tanggal 19 Mei 2014.

Wawancara dengan Bapak Muhammad Amir (sesepuh Muhammadiyah Solo) tanggal 21 Mei 2014.

Wawancara dengan Ibu Hadi Wisarno (Takmir Masjid Al Wustho Mangkunegaran) 5 Juni 2014.

\section{Buku}

Winardi, Uji Nugroho (2010). "Memutihkan yang Merah: Ujian Guru Agama dan Deideologisasi Komunis di Gunung Kidul Pasca-1965” dalam Sri Margana \& Widya Fitrianingsih (peny.). Sejarah Indonesia: Perspektif Lokal dan Global. Persembahan Untuk 70 tahun Prof. Dr. Djoko Suryo. Yogyakarta: Ombak.

Solahudin (2011). Dari NII Sampai JI: Salafy Jihadisme di Indonesia. Depok: Komunitas Bambu. 